Artigos 



\title{
Qualidade da informação: a agenda social da mídia em ano eleitoral presidencial ${ }^{*}$
}

\author{
Luiz Gonzaga Motta** \\ Railssa Peluti Alencar***
}

\section{Resumo}

O objetivo da análise descrita no artigo é observar até que ponto o trabalho de agendamento de jornalistas e candidatos a respeito de temas relacionados às crianças e adolescentes durante o período eleitoral de 2006 aumentou a qualidade da cobertura da mídia. Um trabalho de sensibilização de jornalistas e dos comitês dos candidatos presidenciais foi realizado durante todo o ano eleitoral a fim de qualificar a informação sobre esse tema social. $\bigcirc$ artigo relata uma análise de conteúdo de 54 jornais e quatro telejornais brasileiros que mediu o impacto desse agendamento prévio na qualidade do noticiário do período. Houve um crescimento significativo das notícias sobre o tema. Mas o jornalismo brasileiro (particularmente o telejornalismo) centrou a foco nos candidatos e não nas políticas públicas, perdendo a oportunidade de qualificar a cobertura social com informações relevantes que estavam acessíveis.

Palavras-chave: Qualidade da informação. Cobertura social. Agendamento. Enquadramento. Análise de conteúdo.

* Os autores agradecem a M. Hartz, pela assistência na análise, e a V. Aratanha, L. A. Guerra, E. Mendes, M. A. Amorim, L. Andrade, H. Pena, R. Ribeiro, D. Duarte, D. Peixoto, Max Milliano Melo, A. R. da Cunha, N. Lopes e M. de Sá pela coleta de dados.

** Doutor em Comunicação pela University of Wisconsin, pós-doutor pela Universitat Autonoma de Barcelona. Professor do Programa de Pós-Graduação em Comunicação, Universidade de Brasília. Coordenador do Núcleo de Estudos sobre Mídia e Política. Brasília-DF, Brasil. E-mail: luizmottaunb@yahoo.com.br

*** Mestre em Ciência Política pela Universidade de São Paulo (USP). Graduada em Relações Internacionais. Ex-coordenadora do Núcleo de Monitoramento e Estatísticas da Agência de Notícias dos Direitos da Infância (ANDI) de 2004 a 2008. Publicou diversos artigos relacionados à cobertura da mídia sobre direitos da infância e direitos humanos e coordenou pesquisas produzidas em parcerias ANDI/Unicef, ANDI/Save the Children UK, Rede ANDI Brasil/Instituto Oi Futuro, ANDI/Avina, ANDI/Rede ANDI América Latina, dentre outras. BrasíliaDF, Brasil. E-mail: railssa@uol.com.br 


\section{Information quality: media social agenda in a presidential electoral year \\ Abstract}

The objective of the analysis described in the article is to observe to what extent the previous task of agenda setting journalists and candidates about child and youth problems throughout the 2006 electoral period resulted in the improvement on quality of media reporting. Across the electoral year there was an effort to render sensitive journalist and candidates' committees about this issue. The article reports a content analysis of 54 Brazilian newspaper e 4 newscasts on the subject "children and youth problems" throughout the electoral year to measured the results of the previous effort. There had been a significant growth in space and time about children and youth problems. But Brazilian journalism (particularly newscasts) centralized news reporting on the candidates more than public policies, and lost the opportunity to qualify social reporting when relevant information were at hand.

Keywords: Information quality. Social reporting. Agenda setting. Framing. Content analysis.

\section{Calidad de la información: la agenda social de los medios en un año electoral presidencial \\ Resumén}

El objetivo del análisis descrita en el articulo es observar hasta que punto un agendamiento previo de periodistas y candidatos presidenciales respecto a problemas de los niños y adolescentes durante todo el año electoral de 2006 produjo un mejoramiento en la calidad de la cobertura periodística. Un trabajo de sensibilización de periodistas y comités electorales de los candidatos fue realizado durante todo el año para cualificar la información sobre este tema social. El artículo relata un análisis de contenido de 54 periódicos y 4 tele-noticieros brasileños que midió el impacto de ese agendamiento previo en la calidad de las noticias. Hubo un crecimiento significativo de las noticias sobre el tema. Sin embargo el periodismo brasileño (especialmente los tele-noticieros) ha centrado el foco en los candidatos mas que en las políticas públicas, perdiendo la oportunidad de calificar la cobertura social con informaciones relevantes que estaban disponibles.

Palabras clave: Calidad de la información. Reportaje social. Agenda setting. Framing. Análisis de contenido.

\section{Introdução: mídia e qualidade da cobertura da agenda social}

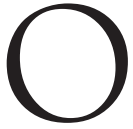

objetivo da análise descrita neste artigo é observar se a mobilização prévia para agendar a mídia e qualificar a informação sobre temas relacionados às crianças e adolescentes 
(I\&A), realizada durante o ano eleitoral de 2006, logrou alterar a qualidade das notícias. Naquele ano, um esforço de agendamento foi desenvolvido pela Unicef e a Agencia de Notícias dos Direitos da Infância (Andi) junto aos comitês dos candidatos presidenciais e às redações dos jornais e telejornais do país. O objetivo era aproveitar o ano eleitoral para pautar o tema na campanha e na mídia, aumentar sua visibilidade e a qualidade da informação, e mobilizar a sociedade em torno dessa temática. $\mathrm{O}$ artigo relata os resultados de uma análise de conteúdo de 54 jornais e quatro telejornais de referencia brasileiros durante 2006 (12 meses), quando foram realizadas eleições presidenciais ${ }^{1}$.

Apesar de ser ainda uma hipótese, a teoria do agenda setting consolidou nos últimos anos a ideia que a mídia estabelece a agenda pública: direciona a atenção, fixa e hierarquiza os temas que serão discutidos pela sociedade durante certo período de tempo. O destaque de certos assuntos pelo jornalismo, diz a teoria, fornece ao publico um mapa de prioridades e relevâncias sociais. Isso ocorre porque, como assinala Thompson (1998), os meios de comunicação de massa consistem hoje na principal forma por meio da qual cidadãos se formam e informam. O jornalismo define "o quê" as pessoas vão discutir e "transfere relevância temática" para as preocupações do público. É a partir dessa transferência hierárquica que a população escolhe os temas a respeito dos quais vale a pena ter uma opinião. Com maior potencia até que as mensagens persuasivas, conclui a teoria, o jornalismo joga um papel central nas imagens que construímos da realidade (MCCOMBS, 2006)².

\footnotetext{
${ }^{1}$ A análise de conteúdo foi realizada pela Andi em parceria com Unicef para monitorar o tratamento das questões relativas à infância e adolescência nos jornais e telejornais brasileiros durante o ano eleitoral de 2006. Análise semelhante foi realizada no ano eleitoral de 2002, possibilitando comparações sobre o agendamento desses temas.

${ }^{2}$ Entre outros estudos citados nesta teoria, o conhecido estudo de Winter e Eyal (1981), por exemplo, comparou a cobertura de capa do The New York Times (do mês antecedente) com os resultados das sondagens de opinião a respeito dos direitos civis pelo Instituto Gallup nos Estados Unidos durante 23 anos. Revelou forte resposta do público a agenda midiática no curto prazo. A cobertura precedia a agenda, demonstrando uma correlação causal. Outros estudos ajudaram a corroborar a hipótese do agendamento publico pelos meios de comunicação e consolidaram a afirmação que os jornalistas têm uma influencia significativa na imagem de mundo de suas audiências (MCCOMBS, 2005, p.53).
} 
A análise aqui apresentada não tem a pretensão nem foi desenhada para verificar se o agendamento prévio obteve subsequente redirecionamento da atenção do público, mas se aproxima da hipótese acima. Assumiu-se que maior quantidade e qualidade na cobertura sobre I\&A teriam uma repercussão indireta sobre a opinião publica, supondo-se que quanto maior exposição desses temas na mídia, mais a sociedade os prioriza nos debates públicos, e quanto maior a profundidade da cobertura, mais alternativas sociais poderiam ser identificadas e implementadas.

\section{O Brasil e a dívida social: o problema infantil e a mídia}

O Brasil tem 61 milhões de crianças e adolescentes, um terço de sua população de 180 milhões. 45\% deles (quase 30 milhões) são pobres. No entanto, a agenda jornalística segue privilegiando escândalos e conflitos internacionais em detrimento dos problemas sociais internos. Em consequência, a agenda social continua relegada pela mídia e parte significativa da sociedade ${ }^{3}$. As editorias de política e de economia ocupam o maior espaço e tempo do noticiário.

Embora tenha havido mudanças significativas nas últimas décadas, o governo não privilegia políticas públicas relativas às crianças e adolescentes. Em 2006, por exemplo, somente 1,47\% de R \$1,14 trilhões executados pela União foram investidos em educação. De acordo, com estudos do Instituto de Estudos Sócio-econômico, o orçamento direcionado pelo governo federal atingiu o correspondente a $2,7 \%$ dos gastos públicos federais - o que significa menos de um dólar investido por dia por criança ou adolescente para garantir seus direitos.

\section{Eleições: oportunidade de observar o social na mídia}

O ano eleitoral de 2006 foi particularmente propício para que a mídia tocasse em ações desenvolvidas pelo governo para aliviar problemas da agenda social, e particularmente o investimento em

\footnotetext{
${ }^{3}$ Ver Que país é este?.Andi-Unicef-Fundação Ayrton Senna. São Paulo: Cortez Editora, 2003. e outras publicações da Andi, particularmente a série Mídia e mobilização social.
} 
crianças e adolescentes. As circunstâncias eleitorais são oportunas para que a mídia pressione os candidatos a apresentem programas de ações centrados na agenda social.

Os quatro candidatos de maior apelo popular representavam posições ideológicas que vão da direita a extrema esquerda ${ }^{4}$. Criouse um momento singular para um debate sobre as questões sociais do país. Em função dessa oportunidade a Andi e Unicef desenvolveram um intenso trabalho de mobilização e qualificação de jornalistas com a finalidade de sensibilizar as redações durante o ano eleitoral $1^{5}$. Apesar das promessas eleitorais serem mais exacerbações retóricas que compromissos de governo, elas tornam público o posicionamento dos candidatos, e constituem subsídios importantes para fundamentar o controle social posterior às eleições.

\section{O desenho da pesquisa: metodologia}

Paralelamente a qualificação dos jornalistas e a mobilização dos comitês, foi realizado um monitoramento sistemático por meio de uma análise de conteúdo dos 54 principais jornais e dos quatro telejornais de maior audiência. A pesquisa relatada neste artigo processou todas as noticias relativas ao universo infanto-juvenil que mencionavam os candidatos ou que tratavam do futuro contexto a ser enfrentado pelo presidente eleito sobre o tema. As noticias foram selecionadas diariamente através de um clipping eletrônico e uma leitura seletiva. As noticias televisivas passaram por critérios semelhantes. Depois de selecionadas, elas foram indexadas a uma base de dados on-line customizada (sistema Empauta), acessada pelos pesquisadores. Esse banco de dados foi associado a um pro-

\footnotetext{
${ }^{4}$ Apesar das candidaturas só terem sido registradas no TSE posteriormente, e a campanha formal se iniciado no dia 6 de julho, as eleições presidenciais dominaram o conteúdo da mídia durante todo o ano. Quatro candidatos com apelo popular ocuparam espaços privilegiados na mídia: o presidente Luiz Inácio Lula da Silva (PT), o ex-governador de São Paulo Geraldo Alckmin (PSDB e PFL) e os senadores Heloisa Helena (PSTU) e Cristovan Buarque (PDT).

${ }^{5}$ Desde 1996 a Andi vem realizando um trabalho de sensibilização dos jornalistas brasileiros para qualificar a cobertura de temas relativos a infância e adolescência, com resultados bastante positivos (ver CANELAS, 2005).
} 
grama em linguagem freeware. As informações permitiram operar a análise estatística discutida em seguida.

\section{Análise dos Resultados}

Evolução da cobertura durante o ano eleitoral

O Gráfico 1 mostra a evolução da cobertura sobre temas da infância e adolescência nos jornais e telejornais brasileiros no ano eleitoral. Para melhor acompanhar as mudanças, o ano de 2006 foi dividido em três períodos: 1 ) período pré-eleitoral (1º de janeiro a 06 de julho, quando as candidaturas existiam potencialmente, mas ainda não haviam sido formalizadas; 2) período eleitoral, quando os candidatos são registrados, a campanha se inicia e realizaram-se os dois turnos (6 de julho a 6 de novembro); 3) período pós-eleitoral (06 de novembro a 31 de dezembro, quando temas eleitorais permanecem na mídia, mas vão arrefecendo).

Gráfico 1 - Evolução da cobertura (geral)

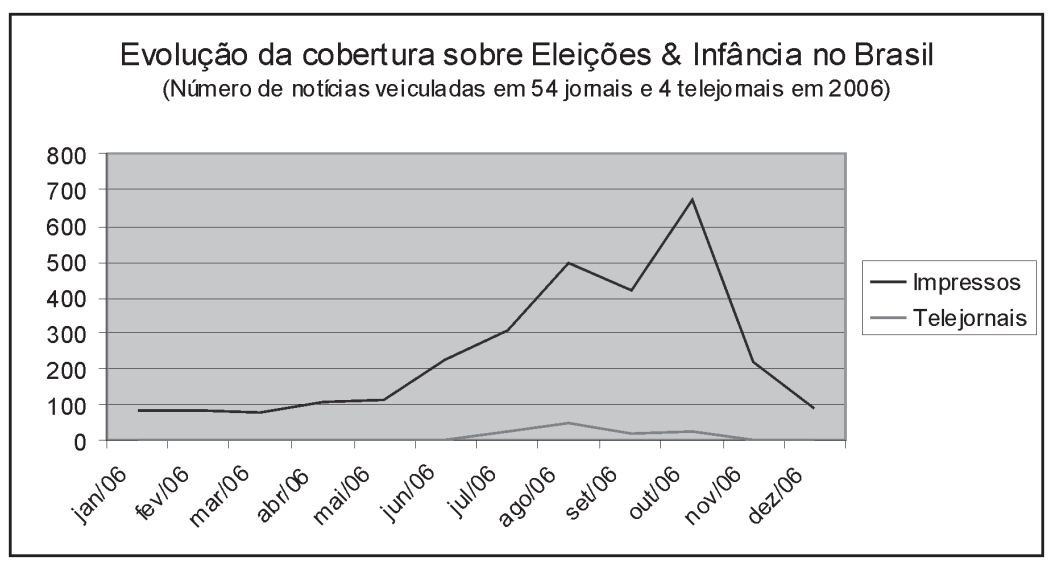

O Gráfico 1 mostra que a cobertura de temas relacionados à infância e adolescência manteve-se baixa nos jornais até o mês de maio, quando se aproximou o período eleitoral. A partir daí, com a definição dos candidatos presidenciais, começa a subir e aumenta significativamente a partir de 6 de julho, quando a campanha 
formal se inicia. Embora apresente ligeira queda entre agosto e setembro, a cobertura sobe, até atingir o clímax nas vésperas do primeiro turno (início de outubro). Durante o segundo turno a cobertura decai vertiginosamente, continuando a decrescer após o período eleitoral. Os telejornais apresentam uma linha relativamente semelhante, embora com um volume de notícias muito abaixo dos jornais impressos. As eleições exerceram, assim, um papel catalisador de temas sobre I\&A na mídia.

Os dados da Tabela 1 confirmam que os temas relativos à I\&A foram incluídos na pauta dos jornais impressos durante o período eleitoral (julho/outubro). Encontraram-se nos 54 jornais impressos 2.911 notícias publicadas durante o ano eleitoral cujos conteúdos estavam relacionados a crianças e adolescentes. Nos 30 dias compreendidos entre 6 de setembro e 6 de outubro, clímax da campanha e véspera do primeiro turno, foram publicadas 675 notícias nos 54 jornais. Em termos de número de notícias, o período que precedeu o segundo turno foi o que alcançou melhores indicadores. Embora sincrônicos, o volume de notícias dos telejornais foi muito menor notícias sobre o tema nos períodos pré e pós-eleitorais. Isso é explicado pelo fato das notícias nos telejornais necessitarem imagens e requererem maior dramatismo, o que nem sempre ocorre nas notícias sobre políticas publicas.

O volume total (2.911) de notícias sobre infância e adolescência publicado no ano nos jornais impressos é bastante significativo, especialmente se confrontado com as 123 notícias apenas publicadas nos jornais brasileiros sobre o tema no ano eleitoral de 2002, quando o monitoramento foi realizado pela primeira vez. Houve, portanto, um crescimento muito expressivo, especialmente levandose em conta que a cobertura política em 2006 esteve bastante condicionada pelos escândalos eleitorais. ${ }^{6}$ Isso revela que o trabalho de sensibilização dos jornalistas, associado a outros fatores, obteve êxito, logrando pautar a mídia.

\footnotetext{
${ }^{6}$ MOTTA, L. G. (2005) revela em estatísticas a preferência dos jornais brasileiros por escândalos políticos, muitos aquecidos e amplificados superficialmente no calor das disputas eleitorais. A excessiva cobertura dos escândalos reduziu espaço na agenda da mídia para outras coberturas durante o período eleitoral.
} 
Tabela 1 - Evolução da cobertura ao longo dos diferentes períodos

\begin{tabular}{l|l|l|l|l}
\hline Período & $\begin{array}{l}\text { Número de notícias } \\
\text { impressas }\end{array}$ & $\%$ & $\begin{array}{l}\text { Número de } \\
\text { notícias } \\
\text { televisivas }\end{array}$ & $\%$ \\
\hline Pré-Eleitoral & 724 & $24,87 \%$ & 6 & $4,65 \%$ \\
\hline Eleitoral (1‥ Turno) & 1.203 & $41,33 \%$ & 96 & $74,42 \%$ \\
\hline Eleitoral (2o. Turno) & 641 & $22,02 \%$ & 19 & $14,73 \%$ \\
\hline Pós-Eleitoral & 343 & $11,78 \%$ & 8 & $6,20 \%$ \\
\hline Total & 2.911 & $100,00 \%$ & 129 & $100,00 \%$ \\
\hline
\end{tabular}

O número de notícias encontradas nos telejornais (129 unidades no total) pode parecer ínfimo se comparado aos jornais impressos, como a Tabela 1 sugere a primeira vista. Mas, deve-se levar em consideração que foram apenas quatro telejornais, enquanto 54 jornais impressos foram pesquisados. Entre 1०. de Janeiro e 29 de outubro (sem contar o período pós-eleitoral) foram transmitidos quase 250 minutos de notícias sobre infância relacionada às eleições, com uma média de 2 minutos por notícia. Deve-se levar em conta também a intensa cobertura dos escândalos nos telejornais, que deixou pouco tempo para outros temas.

\section{Temas predominantes nas coberturas}

A análise identificou os temas mais recorrentes nas notícias sobre infância e adolescência. Como se pode observar na Tabela 2, sem variar muito nos três períodos, o tema "educação" (que diz respeito diretamente a infância e adolescência) foi o mais frequente nos jornais (sempre acima de 40\%), e particularmente nos telejornais, onde chegou a $66.67 \%$ do total das notícias durante o período eleitoral. Deve-se relembrar que o candidato C. Buarque focou todo o seu programa na educação, inflacionando o tema. Em decorrência, os outros candidatos viram-se na contingência de segui-lo porque educação tem forte apelo eleitoral. As porcentagens referem-se ao total de notícias que abordou cada um dos candidatos no período correspondente. 
Tabela 2 - Temas recorrentes das notícias

\begin{tabular}{|c|c|c|c|c|}
\hline \multicolumn{5}{|l|}{ Tema principal } \\
\hline $\begin{array}{l}\text { Período } \\
\text { Tema }\end{array}$ & Pré-Eleitoral & $\begin{array}{l}\text { Eleitoral } \\
1^{\text {o Turno }}\end{array}$ & $\begin{array}{l}\text { Eleitoral } \\
2^{\circ} \text { Turno }\end{array}$ & Pós-Eleitoral \\
\hline * Educação & $47,65 \%$ & $44,64 \%$ & $46,33 \%$ & $40,52 \%$ \\
\hline Vários níveis de ensino & $37,29 \%$ & $37,24 \%$ & $35,41 \%$ & $31,78 \%$ \\
\hline $\begin{array}{l}\text { Acesso ao Ensino } \\
\text { Superior }\end{array}$ & $3,73 \%$ & $3,33 \%$ & $5,15 \%$ & $5,83 \%$ \\
\hline $\begin{array}{l}\text { Educação } \\
\text { Profissionalizante }\end{array}$ & $1,66 \%$ & $0,17 \%$ & $0,00 \%$ & $0,29 \%$ \\
\hline Ensino Fundamental & $1,10 \%$ & $1,16 \%$ & $1,25 \%$ & $0,87 \%$ \\
\hline Analfabetismo de Jovens & $0,69 \%$ & $0,50 \%$ & $0,62 \%$ & $0,29 \%$ \\
\hline $\begin{array}{l}\text { Educação - Educação In- } \\
\text { fantil }\end{array}$ & $0,14 \%$ & $0,25 \%$ & $0,16 \%$ & $0,00 \%$ \\
\hline $\begin{array}{l}\text { Educação - } \\
\text { Ensino Médio }\end{array}$ & $0,14 \%$ & $0,83 \%$ & $0,62 \%$ & $0,29 \%$ \\
\hline $\begin{array}{l}\text { Educação de Jovens } \\
\text { (EJA) }\end{array}$ & $0,00 \%$ & $0,00 \%$ & $0,00 \%$ & $0,00 \%$ \\
\hline $\begin{array}{l}\text { Outros assuntos relaciona- } \\
\text { dos a Educação }\end{array}$ & $2,90 \%$ & $1,16 \%$ & $3,12 \%$ & $1,17 \%$ \\
\hline Direitos \& Justiça & $43,24 \%$ & $38,07 \%$ & $44,46 \%$ & $49,27 \%$ \\
\hline $\begin{array}{l}\text { Pobreza \& Exclusão } \\
\text { Social }\end{array}$ & $42,13 \%$ & $33,17 \%$ & $39,78 \%$ & $46,06 \%$ \\
\hline $\begin{array}{l}\text { Pobreza \& Exclusão So- } \\
\text { cial/Especificando Crian- } \\
\text { ças \& Adolescentes }\end{array}$ & - & $3,57 \%$ & $2,18 \%$ & $2,04 \%$ \\
\hline $\begin{array}{l}* \text { Marco Legal, Jurídico \& } \\
\text { Institucional }\end{array}$ & $0,83 \%$ & $3,16 \%$ & $1,56 \%$ & $0,87 \%$ \\
\hline $\begin{array}{l}\text { * Convivência Familiar/ } \\
\text { Direitos de Família }\end{array}$ & $0,28 \%$ & $0,50 \%$ & $0,47 \%$ & $0,29 \%$ \\
\hline Cor/Etnia & $0,00 \%$ & $0,50 \%$ & $0,47 \%$ & $0,00 \%$ \\
\hline Gênero & $0,00 \%$ & $0,00 \%$ & $0,00 \%$ & $0,00 \%$ \\
\hline Deficiências & $0,00 \%$ & $0,08 \%$ & $0,00 \%$ & $0,00 \%$ \\
\hline Questões Demográficas & $0,00 \%$ & $0,25 \%$ & $0,00 \%$ & $0,00 \%$ \\
\hline $\begin{array}{l}\text { * Medidas de Reinserção } \\
\text { Social }\end{array}$ & $3,59 \%$ & $0,50 \%$ & $1,09 \%$ & $0,00 \%$ \\
\hline Trabalho Legal & $1,52 \%$ & $1,25 \%$ & $0,94 \%$ & $0,87 \%$ \\
\hline
\end{tabular}




\begin{tabular}{|c|c|c|c|c|}
\hline Habitação & $0,97 \%$ & $0,58 \%$ & $0,00 \%$ & $0,00 \%$ \\
\hline * Trabalho Infantil & $0,83 \%$ & $0,75 \%$ & $0,16 \%$ & $0,58 \%$ \\
\hline Comportamento & $0,28 \%$ & $6,23 \%$ & $4,06 \%$ & $3,21 \%$ \\
\hline Meio Ambiente & $0,28 \%$ & $0,00 \%$ & $0,00 \%$ & $0,58 \%$ \\
\hline $\begin{array}{l}\text { Mídia (TV, Rádio, } \\
\text { Impressos e Internet) }\end{array}$ & $0,28 \%$ & $0,00 \%$ & $0,00 \%$ & $1,17 \%$ \\
\hline $\begin{array}{l}\text { * Exploração \& Abuso } \\
\text { Sexual }\end{array}$ & $0,28 \%$ & $0,33 \%$ & $0,00 \%$ & $0,29 \%$ \\
\hline * Saúde & $0,83 \%$ & $2,08 \%$ & $1,42 \%$ & $1,75 \%$ \\
\hline Saúde Materna & $0,41 \%$ & $1,16 \%$ & $0,94 \%$ & $0,58 \%$ \\
\hline Mortalidade Infantil & $0,28 \%$ & $0,33 \%$ & $0,16 \%$ & $0,58 \%$ \\
\hline Saúde - Nutrição & $0,00 \%$ & $0,25 \%$ & $0,16 \%$ & $0,00 \%$ \\
\hline Saúde - Aids & $0,00 \%$ & $0,00 \%$ & $0,00 \%$ & $0,00 \%$ \\
\hline $\begin{array}{l}\text { Saúde - Malária, Hansení- } \\
\text { ase e Tuberculose }\end{array}$ & $0,00 \%$ & $0,08 \%$ & $0,00 \%$ & $0,00 \%$ \\
\hline $\begin{array}{l}\text { Outros assuntos relaciona- } \\
\text { dos a Saúde }\end{array}$ & $0,14 \%$ & $0,25 \%$ & $0,16 \%$ & $0,58 \%$ \\
\hline Consumo & $0,14 \%$ & $0,00 \%$ & $0,00 \%$ & $0,58 \%$ \\
\hline Acesso à Água Potável & $0,14 \%$ & $0,00 \%$ & $0,00 \%$ & $0,00 \%$ \\
\hline *Violência & $0,00 \%$ & $0,58 \%$ & $0,47 \%$ & $0,00 \%$ \\
\hline $\begin{array}{l}\text { Violência praticada contra } \\
\text { crianças e adolescentes }\end{array}$ & $0,00 \%$ & $0,08 \%$ & $0,31 \%$ & $0,00 \%$ \\
\hline $\begin{array}{l}\text { Violência praticada por } \\
\text { crianças e adolescentes }\end{array}$ & $0,00 \%$ & $0,00 \%$ & $0,16 \%$ & $0,00 \%$ \\
\hline $\begin{array}{l}\text { Violência entre crianças e } \\
\text { adolescentes }\end{array}$ & $0,00 \%$ & $0,08 \%$ & $0,00 \%$ & $0,00 \%$ \\
\hline Violência Institucional & $0,00 \%$ & $0,08 \%$ & $0,00 \%$ & $0,00 \%$ \\
\hline Gangues & $0,00 \%$ & $0,00 \%$ & $0,00 \%$ & $0,00 \%$ \\
\hline Conflitos Armados & $0,00 \%$ & $0,00 \%$ & $0,00 \%$ & $0,00 \%$ \\
\hline Outros tipos de Violência & $0,00 \%$ & $0,33 \%$ & $0,00 \%$ & $0,00 \%$ \\
\hline Drogas & $0,00 \%$ & $0,58 \%$ & $0,31 \%$ & $0,58 \%$ \\
\hline $\begin{array}{l}\text { Abandono, Abrigos \& } \\
\text { Situação de Rua }\end{array}$ & $0,00 \%$ & $0,25 \%$ & $0,00 \%$ & $0,00 \%$ \\
\hline Desaparecidos & $0,00 \%$ & $0,00 \%$ & $0,00 \%$ & $0,00 \%$ \\
\hline
\end{tabular}




\begin{tabular}{l|l|l|l|l}
\hline $\begin{array}{l}\text { Migração ou } \\
\text { Deslocamento }\end{array}$ & $0,00 \%$ & $0,58 \%$ & $0,00 \%$ & $0,00 \%$ \\
\hline Sexualidade & $0,00 \%$ & $0,08 \%$ & $0,16 \%$ & $0,00 \%$ \\
\hline Cultura & $0,00 \%$ & $0,08 \%$ & $0,31 \%$ & $0,58 \%$ \\
\hline Esporte \& Lazer & $0,00 \%$ & $0,25 \%$ & $0,31 \%$ & $0,00 \%$ \\
\hline $\begin{array}{l}\text { Total de notícias } \\
\text { analisadas }\end{array}$ & 724 & 1.203 & 641 & 343 \\
\hline
\end{tabular}

(*) Os itens assinalados correspondem aos temas alvo de ações de mobilização da Andi e Unicef.

O segundo tema mais frequente foi "Pobreza \& Exclusão Social" (também diz respeito à crianças e adolescentes) que se manteve próximo ou superior a $40 \%$ e, no período pós-eleitoral, suplanta o tema Educação, chegando a 46.06\%. Este índice alto decorre, provavelmente, da discussão do programa "Bolsa Família" (um programa assistencialista do Governo Lula) durante todo o período eleitoral. Essas discussões incluíam debates sobre os procedimentos deste programa, tanto pelo candidato da situação como pela oposição, que o criticava e solicitava reformulações.

O tema "Comportamento" aparece com destaque nos telejornais $(5.22 \%)$ e jornais impressos $(6.23 \%$ e $4.06 \%$ respectivamente) durante os períodos da campanha eleitoral, certamente por causa das matérias sobre jovens eleitores de 16 anos, que votavam pela primeira vez. O tema "Habitação" aparece também com algum destaque nos telejornais durante o primeiro turno (5.22\%) provavelmente por causa das referenciais do candidato G. Alckmin ao seu programa de habitação popular enquanto governador de São Paulo. Dignos também de menção os índices relativos ao tema "Marco Legal, Jurídico e Institucional" nos jornais (3.16\%) e nos telejornais (3.48\%). Isso indica que os candidatos fizeram referências aos estatutos, jurisprudência e conselhos que garantem os direitos das crianças e adolescentes. A ANDI e outras ONGs têm feito um trabalho sistemático nos últimos anos procurando inserir esses marcos legais na cobertura jornalística. Os dados parecem indicar que estão conseguindo relativo êxito. 


\section{Enquadramentos e a qualidade das notícias sobre infância}

Entman (2004) define enquadramento como um processo de seleção e hierarquização de alguns aspectos da realidade pelos jornalistas em suas práticas de trabalho. A ocorrência de um evento qualquer ativa paradigmas na mente dos jornalistas estimulando o uso de certas imagens ressonantes na construção das notícias. Os "objetos" da realidade são "enquadrados" (framed) como "um problema, uma solução ou uma questão moral de fundo”. Os enquadramentos jornalísticos promovem, portanto, interpretações particulares das questões. Assim, incidem sobre os eventos, atores e questões políticas.

Para os interesses de nossa análise, o enquadramento contextual pode determinar uma maior ou menor qualidade da informação veiculada. Se a notícia restringe-se ao factual, a qualidade é restrita; se relatar o contexto, as políticas públicas e propostas de solução, a qualidade da informação se eleva. Em ano eleitoral essa qualidade adquire relevância particular porque os enquadramentos podem subsidiar os públicos com novos ângulos e qualificar as discussões na busca de soluções.

Conforme a Tabela 3, procuramos observar três enquadramentos contextuais das notícias sobre I\&A: 1) a notícia situa socialmente a questão; 2) a notícia aborda políticas públicas; 3) a notícia traz propostas para solucionar os problemas. Notícias que trazem esses enquadramentos promovem uma maior qualidade da informação porque contextualizam a questão. Comentaremos cada enquadramento separadamente primeiro, e concluiremos com breve interpretação.

1) Situação atual da $I \& A$ : no caso dos jornais impressos, a Tabela 3 revela que a proporção de notícias que situou o contexto dos problemas da I\&A é relativamente alta, mantendo-se em volta dos $40 \%$ para quase todos os candidatos. Há pequenas variações não muito significativas, indicando que todos os candidatos (e a mídia) preocuparam-se em situar os problemas oferecendo melhor qualidade informativa ao eleitor. No caso dos telejornais, a exceção é o índice comparativamente baixo (10.5\%) para G. Alckimin, difícil de ser explicado no escopo desta análise. Fora essa exceção, a 
média pode ser considerada elevada tomando-se em conta o clima polarizado, o fascínio dos jornalistas pelos escândalos e a pressa natural da cobertura eleitoral.

\section{Tabela 3 - Enquadramentos contextuais}

Enquadramento dos Candidatos nas Notícias (*)

\begin{tabular}{|c|c|c|c|c|c|c|}
\hline 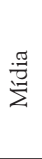 & $\begin{array}{l}\text { Enquadramento/ } \\
\text { Candidato }\end{array}$ & $\begin{array}{l}\text { Luís } \\
\text { Inácio } \\
\text { Lula da } \\
\text { Silva } \\
\text { (PT) }\end{array}$ & $\begin{array}{l}\text { Geraldo } \\
\text { Alckmin } \\
\text { (PSDB) }\end{array}$ & $\begin{array}{l}\text { Cristóvam } \\
\text { Buarque } \\
\text { (PDT) }\end{array}$ & $\begin{array}{l}\text { Heloísa } \\
\text { Helena } \\
\text { (PSOL) }\end{array}$ & $\begin{array}{l}\text { Nanicos, } \\
\text { outros Pré- } \\
\text { Candidatos } \\
\text { e Candidato } \\
\text { indefinido }\end{array}$ \\
\hline \multirow{4}{*}{ 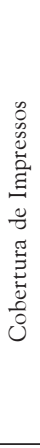 } & $\begin{array}{l}\text { Aborda Situação } \\
\text { Atual } \\
\text { da Infância \& } \\
\text { Adolescência }\end{array}$ & $43,79 \%$ & $35,59 \%$ & $39,05 \%$ & $40,94 \%$ & $50,79 \%$ \\
\hline & $\begin{array}{l}\text { Aborda Políticas } \\
\text { Públicas Atuais } \\
\text { para Infância \& } \\
\text { Adolescência }\end{array}$ & $90,10 \%$ & $63,42 \%$ & $39,76 \%$ & $60,63 \%$ & $29,52 \%$ \\
\hline & $\begin{array}{l}\text { Aborda Propostas } \\
\text { do Candidato } \\
\text { para Infância \& } \\
\text { Adolescência }\end{array}$ & $55,04 \%$ & $68,19 \%$ & $89,29 \%$ & $70,08 \%$ & $38,41 \%$ \\
\hline & $\begin{array}{l}\text { Total de notícias } \\
\text { analisadas }\end{array}$ & 1.706 & 503 & 420 & 127 & 315 \\
\hline \multirow{4}{*}{ 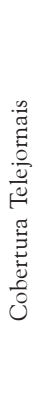 } & $\begin{array}{l}\text { Aborda Situação } \\
\text { Atual da Infância } \\
\text { \& Adolescência }\end{array}$ & $38,47 \%$ & $10,53 \%$ & $39,47 \%$ & $43,48 \%$ & $60,00 \%$ \\
\hline & $\begin{array}{l}\text { Aborda Políticas } \\
\text { Públicas Atuais } \\
\text { para Infância \& } \\
\text { Adolescência }\end{array}$ & $57,69 \%$ & $31,58 \%$ & $15,79 \%$ & $8,70 \%$ & $5,00 \%$ \\
\hline & $\begin{array}{l}\text { Aborda Propostas } \\
\text { do Candidato } \\
\text { para Infância \& } \\
\text { Adolescência }\end{array}$ & $61,54 \%$ & $78,95 \%$ & $76,32 \%$ & $69,57 \%$ & $15,00 \%$ \\
\hline & $\begin{array}{l}\text { Total de notícias } \\
\text { analisadas }\end{array}$ & 26 & 19 & 38 & 23 & 20 \\
\hline
\end{tabular}

(*) As porcentagens referem-se ao total de notícias que abordou cada um dos candidatos no período

2) Políticas públicas - A Tabela 3 revela índices altos, com diferenças acentuadas e significativas. Como se nota, as notícias sobre o candidato Lula tiveram um altíssimo índice de menção 
de políticas públicas, acima de $90 \%$ nos jornais e de $58 \%$ nos telejornais. Provavelmente porque o candidato da situação dedicou atenção aos seus próprios programas de assistência social e de educação, para valorizá-los. Os índices dos outros candidatos caem comparativamente, revelando que candidatos da oposição evitaram mencionar as políticas públicas, provavelmente pressupondo que a simples menção beneficiaria a situação.

3) Propostas - Aqui também os índices são altos, mas diferentes dos anteriores. A direção se inverte. Isto é, os índices das notícias relativas ao candidato da situação que trazem propostas para a I\&A são mais baixos enquanto os índices das notícias referentes aos candidatos da oposição são mais altos. $\mathrm{O}$ índice mais alto refere-se aos jornais impressos em relação ao candidato C. Buarque: quase $90 \%$ das notícias relativas a este candidato trouxeram propostas em seus conteúdos, a maioria delas, provavelmente, relativas à educação, tema predominante na campanha deste candidato. Neste item, é a oposição que realça propostas, mais que o candidato da situação.

Os índices para os três tipos de enquadramentos observados são relativamente altos, especialmente levando-se em conta os conflitos pessoais e partidários da campanha presidencial, o clima emocional, o grande número de denúncias e acusações e a pressa, típica da cobertura desses momentos políticos. Isso indica que, apesar de tudo, a qualidade do noticiário tanto dos jornais impressos quanto dos telejornais foi boa, porque incluiu as políticas públicas e propostas de solução. Os índices revelam também que o clima de disputa eleitoral interferiu como uma variável interveniente, direcionando o noticiário sobre o candidato da situação para uma posição (salientou as políticas) e o noticiário sobre os candidatos da oposição para outra posição (salientaram as propostas).

\section{Informações sobre políticas públicas para crianças}

A qualidade das informações sobre as políticas públicas para infância e adolescência pode ser mais bem observada na Tabela 4. Elas revelam o uso dos recursos que os jornalistas tinham à disposição e poderiam incluir nas notícias para elevar a qualidade 
da informação: indicadores sociais e econômicos, marcos legais, dados orçamentários e outros.

Tabela 4 - Qualidade das informações

\begin{tabular}{|c|c|c|c|c|c|}
\hline \multicolumn{6}{|c|}{$\begin{array}{l}\text { Recursos utilizados nas notícias que formularam avaliações sobre } \\
\text { Políticas Públicas voltadas para Infância \& Adolescência }\end{array}$} \\
\hline Candidato & $\begin{array}{l}\text { Luís } \\
\text { Inácio } \\
\text { Lula da } \\
\text { Silva (PT) }\end{array}$ & $\begin{array}{l}\text { Geraldo } \\
\text { Alckmin } \\
\text { (PSDB) }\end{array}$ & $\begin{array}{l}\text { Cristóvam } \\
\text { Buarque } \\
\text { (PDT) }\end{array}$ & $\begin{array}{l}\text { Heloísa } \\
\text { Helena } \\
\text { (PSOL) }\end{array}$ & $\begin{array}{l}\text { Outros } \\
\text { Candidatos }\end{array}$ \\
\hline \multicolumn{6}{|l|}{$\begin{array}{l}\text { Recursos } \\
\text { utilizados }\end{array}$} \\
\hline $\begin{array}{l}\text { Menciona } \\
\text { indicadores } \\
\text { sociais }\end{array}$ & $16,71 \%$ & $3,38 \%$ & $9,76 \%$ & $12,60 \%$ & $5,08 \%$ \\
\hline $\begin{array}{l}\text { Menciona } \\
\text { Indicadores } \\
\text { Econômicos }\end{array}$ & $8,09 \%$ & $0,80 \%$ & $0,71 \%$ & $5,51 \%$ & $1,59 \%$ \\
\hline $\begin{array}{l}\text { Menciona } \\
\text { Direitos da } \\
\text { Infância }\end{array}$ & $0,23 \%$ & $0,40 \%$ & $0,24 \%$ & $0,00 \%$ & $0,00 \%$ \\
\hline $\begin{array}{l}\text { Menciona } \\
\text { Marco Legal } \\
\text { ou Jurídico }\end{array}$ & $2,17 \%$ & $0,60 \%$ & $0,48 \%$ & $0,00 \%$ & $1,59 \%$ \\
\hline $\begin{array}{l}\text { Menciona } \\
\text { Dados } \\
\text { Orçamentários }\end{array}$ & $5,51 \%$ & $0,80 \%$ & $3,10 \%$ & $2,36 \%$ & $0,63 \%$ \\
\hline $\begin{array}{l}\text { Menciona } \\
\text { Impressões } \\
\text { Pessoais }\end{array}$ & $13,48 \%$ & $11,53 \%$ & $14,76 \%$ & $27,56 \%$ & $8,57 \%$ \\
\hline $\begin{array}{l}\text { Menciona um } \\
\text { caso individual } \\
\text { ou específico }\end{array}$ & $3,87 \%$ & $2,19 \%$ & $2,86 \%$ & $1,57 \%$ & $1,90 \%$ \\
\hline $\begin{array}{l}\text { Total de } \\
\text { notícias } \\
\text { analisadas }\end{array}$ & 1.706 & 503 & 420 & 127 & 315 \\
\hline
\end{tabular}

A Tabela 4 mostra que os indicadores sociais aparecem em maior escala nas notícias sobre o candidato Lula, provavelmente porque ele citou frequentemente os indicadores positivos que se referiam ao seu próprio governo. Embora em menor escala, os 
indicadores estão presentes também nas notícias sobre H. Helena e C. Buarque e G. Alkimin, em ordem descendente. Os indicadores econômicos aparecem novamente com uma frequência muito maior nas notícias sobre Lula, distanciado significativamente de $\mathrm{H}$. Helena. Surpreendentemente, estão ausentes no caso dos outros candidatos. Coisa semelhante ocorre com os dados orçamentários, muito presentes nas notícias sobre Lula, vindo em segundo lugar o noticiário de C. Buarque. As estatísticas revelam que recursos disponíveis como os marcos legais e os direitos da criança e adolescentes, que se utilizados qualificariam o noticiário, praticamente não foram citados pelos candidatos nem utilizados pelos jornalistas. Isso indica a necessidade de um agendamento específico sobre os marcos legais, pois os candidatos ignoraram, ou os jornalistas não utilizam, essas referencias, empobrecendo o noticiário.

A Tabela 4 indica ainda que a menção a impressões pessoais sobre as políticas públicas para a infância, que o jornalista recolhe junto ao próprio candidato, têm um percentual muito elevado se comparado a outros recursos que poderiam ser utilizados pelos jornalistas, superando em larga escala outros recursos disponíveis já mencionados. As impressões pessoais do candidato Alckmin por exemplo são três vezes maiores que os indicadores sociais citados nas matérias sobre ele. No caso dos candidatos H. Helena e Buarque, é duas vezes maior. Isso revela que a cobertura esteve muito centrada na pessoa dos candidatos, mencionando menos as questões programáticas.

A centralização das questões no candidato e não nas políticas públicas parece ser um hábito arraigado do jornalismo brasileiro. Basta observar o baixo índice de casos individuais relatados pelo noticiário durante o período eleitoral. Inexplicavelmente, histórias e "casos" individuais, que enriqueceriam o noticiário, têm um percentual muito baixo nas notícias de todos os candidatos.

A centralização do noticiário na pessoa dos candidatos é corroborada pela Tabela 5. Ela mostra que, no caso dos telejornais, só $6.2 \%$ das notícias tiveram origem nos âncoras dos telejornais, 40.6\% nas narrações dos repórteres enquanto $53.1 \%$ tiveram origem nos próprios candidatos. Esses percentuais são uma evidencia forte do excessivo foco do noticiário na pessoa dos candidatos que, aparentemente, lograram pautar a mídia. 
Tabela 5 - Centralidade das notícias

\begin{tabular}{l|l|l}
\hline \multicolumn{3}{c}{$\begin{array}{l}\text { Momento da notícia no qual assuntos relacionados a } \\
\text { Infância \& Adolescência são comentados nos telejornais }\end{array}$} \\
\hline Narração do Âncora & 9 & $6.2 \%$ \\
\hline Narração do Repórter & 59 & $40.6 \%$ \\
\hline Inserção do candidato ou de integrante de sua campanha & 77 & $53.1 \%$ \\
\hline Total de Notícias Analisadas & 121 & $100 \%$ \\
\hline
\end{tabular}

A análise da qualidade do noticiário sobre as propostas para solucionar problemas da I\&A também foi analisada. A proposta era indagar se as notícias dos jornais impressos discutiram a viabilidade jurídica, política, gerencial e orçamentária das propostas dos candidatos. Levando-se em conta apenas o período eleitoral, observa-se que os índices de discussão da viabilidade das propostas são bastante baixos nas notícias de todos os candidatos, em todos os períodos, exceção para C. Buarque e H. Helena, cujas noticias discutem em percentuais razoáveis a viabilidade administrativa e orçamentária das propostas (mas, não a viabilidade jurídica e política).

Os dados não revelam, porém, se a iniciativa de discutir a viabilidade das propostas parte do candidato ou dos jornalistas. Como C. Buarque insistiu muito na questão da educação como solução para os problemas do país, é possível que essa insistência tenha contaminado parte do discurso dos outros candidatos, como já dissemos. Com certa evidencia, pelo menos, a cobertura a respeito da viabilidade das propostas deste candidato: o percentual de viabilidade das propostas deste candidato questionada nas notícias é o único realmente significativo (5.48\%).

Os baixos índices desta parte da análise revelam ainda que, embora o noticiário tenha dado destaque às propostas para a I\&A, a viabilidade administrativa, jurídica ou financeira delas não foi questionada pelos jornalistas (exceção para o candidato C. Buarque, como vimos). Se tivessem discutido a viabilidade das propostas os jornalistas teriam elevado certamente a qualidade do noticiário e 
dos debates eleitorais. Principalmente porque, no período eleitoral, há uma tendência dos candidatos de fazer propostas impossíveis de serem viabilizadas ou destacar mais os resultados esperados (tipo"criarei $x$ novos empregos!, etc.) que os processos e a viabilidade para efetivar tais promessas.

Tal cenário mostra aspectos do noticiário dos jornais impressos relacionados à governabilidade e à gestão das propostas. Isto é, se o noticiário sobre os candidatos levantou ou propôs ações integradas, avaliação de políticas, perspectiva dos direitos humanos, transparência na gestão publica e outros aspectos relacionados à boa gestão. No geral, nota-se um baixo índice de menção de todos os aspectos relacionados à gestão das propostas, tanto em termos de eficácia, participação popular, sustentabilidade e transparência. Os dados revelam que essas questões não entraram na pauta dos jornalistas quando cobriam as propostas dos candidatos para a infância e adolescência, indicando certa rapidez e superficialidade no tratamento das questões. Farto material havia sido distribuído previamente junto aos comitês dos candidatos sobre essas questões, assim como junto as redações.

\section{Interpretação e conclusões}

A realização de eleições presidenciais proporcionou as condições de um laboratório natural quase-experimental para observar a relação entre a mídia e a política. Valendo-se do ano de eleitoral de 2006 a pesquisa buscou detectar se a mídia brasileira, devidamente agendada, aproveitou a oportunidade para cobrir criticamente as questões da I\&A. Embora a pesquisa não tenha um desenho experimental, o trabalho prévio de agendamento das redações e dos candidatos pode ser compreendido, com alguma reserva, como uma variável antecedente. A qualidade da cobertura dos temas ligados a I\&A nas notícias sobre os candidatos, como variável dependente. E o processo eleitoral, com seu valor-notícia intrínseco, grosso modo, pode ser entendido como variável interveniente.

Os dados revelaram um crescimento significativo do noticiário sobre o tema, quando comparados com os resultados da pesquisa de 2002. Em 2006, os índices foram mais elevados durante o período 
Tabela 6 - Aspectos relacionados à Governabilidade \& Governança das Propostas dos Candidatos para Infância \& Adolescência $\left({ }^{*}\right)$

\begin{tabular}{|c|c|c|c|c|}
\hline & Aspectos/Período & $\begin{array}{l}\text { Pré- } \\
\text { Eleitoral }\end{array}$ & Eleitoral & Pós-Eleitoral \\
\hline \multirow{3}{*}{ 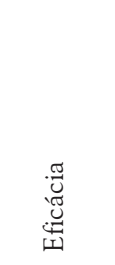 } & $\begin{array}{l}\text { Apresenta ou propõe ação integrada } \\
\text { entre instituições governamentais } \\
\text { vinculadas a I\&A }\end{array}$ & $2,67 \%$ & $1,41 \%$ & $1,46 \%$ \\
\hline & $\begin{array}{l}\text { Apresenta ou propõe avaliação polí- } \\
\text { ticas públicas voltadas } \mathrm{p} / \mathrm{I} \& \mathrm{~A}\end{array}$ & $1,18 \%$ & $3,31 \%$ & $2,91 \%$ \\
\hline & Aborda responsabilidade fiscal & $0,82 \%$ & $2,66 \%$ & $3,49 \%$ \\
\hline \multirow{3}{*}{ 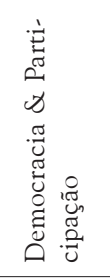 } & $\begin{array}{l}\text { Utiliza perspectiva de Direitos } \\
\text { Humanos/ Direitos da Infância }\end{array}$ & $0,69 \%$ & $2,39 \%$ & $0,88 \%$ \\
\hline & $\begin{array}{l}\text { Aborda liberdade de imprensa ou } \\
\text { liberdade de expressão }\end{array}$ & $0,14 \%$ & $0,11 \%$ & $1,17 \%$ \\
\hline & $\begin{array}{l}\text { Apresenta ou propõe participação } \\
\text { sociedade civil na formulação de } \\
\text { propostas para a I\&A }\end{array}$ & $2,62 \%$ & $1,95 \%$ & $1,75 \%$ \\
\hline \multirow{2}{*}{ 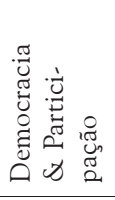 } & $\begin{array}{l}\text { Faz referência ao eleitorado adoles- } \\
\text { cente/jovem }\end{array}$ & $0,14 \%$ & $5,48 \%$ & $0,29 \%$ \\
\hline & $\begin{array}{l}\text { Faz referência explícita aos Objetivos } \\
\text { de Desenvolvimento do Milênio ou } \\
\text { Um Mundo para as Crianças }\end{array}$ & $0,28 \%$ & $0,38 \%$ & $0,00 \%$ \\
\hline \multirow{3}{*}{ 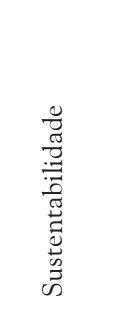 } & $\begin{array}{l}\text { Aborda o Sistema de Garantias de } \\
\text { Direitos ou instituições vinculadas } \\
\text { a ele }\end{array}$ & $0,08 \%$ & $0,48 \%$ & $0,29 \%$ \\
\hline & $\begin{array}{l}\text { Menciona compromissos anterior- } \\
\text { mente firmados pelo candidato para } \\
\text { I\&A }\end{array}$ & $2,10 \%$ & $7,32 \%$ & $4,96 \%$ \\
\hline & $\begin{array}{l}\text { Aborda corrupção ou mecanismos de } \\
\text { combate à corrupção }\end{array}$ & $3,75 \%$ & $3,48 \%$ & $3,21 \%$ \\
\hline \multirow{2}{*}{ 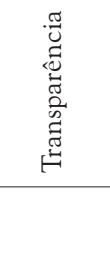 } & $\begin{array}{l}\text { Aborda transparência de informações } \\
\text { e da gestão pública }\end{array}$ & $0,02 \%$ & $0,43 \%$ & $0,58 \%$ \\
\hline & $\begin{array}{l}\text { Total de notícias analisadas em cada } \\
\text { período }\end{array}$ & 724 & 1.844 & 343 \\
\hline
\end{tabular}

(*) As porcentagens referem-se ao total de notícias do período correspondente. 
eleitoral propriamente dito que nos períodos pré e pós-eleitoral. Isso demonstra que, pautados ou não pelo trabalho de agendamento, os candidatos trouxeram os temas sobre a infância e adolescência para a campanha, e a mídia deu destaque a eles. O aumento é mais significativo se levarmos em conta que, durante o transcurso da campanha, a mídia foi tomada por um frenesi de denuncismo, que ofuscaram as discussões de propostas.

O aumento da cobertura da I\&A durante o ano de 2006 foi inflacionado, entretanto, por dois únicos grandes temas: educação e exclusão social. Educação foi o assunto relacionado a crianças e adolescentes mais presente, obtendo índices acima de $40 \%$ entre todos os temas devido ao fato de um dos candidatos ter centrado sua campanha unicamente na educação. As noticias relativas a esse candidato tiveram alto índice de menção a educação. Isso parece ter inflacionado o discurso dos concorrentes, e consequentemente, a cobertura total da mídia.

Um segundo tema que fez os índices das notícias sobre I\&A crescerem relativamente às eleições anteriores foi pobreza e exclusão social (sub-tema de Direito \& Justiça), que manteve percentuais superiores a $40 \%$. Aqui, há outra explicação político-administrativa: o tema apareceu na cobertura por causa do programa Bolsa Família, do Governo Lula, assunto polemizado durante a campanha eleitoral.

Outros temas de atualidade relacionados à I\&A estiveram surpreendentemente ausentes, como saúde e violência, por exemplo. O tema da violência havia recebido ampla cobertura na mídia nos meses anteriores à eleição de 2006 e esperava-se que aparecessem na campanha propostas de solução, o que não ocorreu. Por ocasião dos atentados de autoria do PCC em São Paulo e do questionamento da política de segurança promovida pelo Governo do Estado durante a gestão do principal candidato oponente (G. Alckmin), o tema havia ocupado amplos espaços na mídia. Era de se esperar, portanto, que estivesse presente no conjunto de notícias durante o período eleitoral. Contudo, o debate não enfocou a questão embora as causas da violência e as raízes do crime organizado estejam vinculadas ao recrutamento de crianças e adolescentes da periferia.

O crescimento significativo da cobertura sobre I\&A esconde outros problemas da cobertura. Os dados revelam que a qualidade 
da cobertura foi baixa. Apesar da menção frequente das políticas publicas e programas para o setor, principalmente nos jornais impressos, os jornalistas não foram críticos em relação a essas propostas, não questionaram sua viabilidade orçamentária nem a sua eficácia. A menção às políticas publicas é mais frequente no período pré que durante o período eleitoral, sugerindo novamente que no transcurso da campanha, os conflitos eleitorais exacerbados e os escândalos ofuscaram outros temas.

Outro fato significativo revelado pela pesquisa foi a cobertura excessivamente centralizada na figura do candidato. Grande parte das notícias que tratavam de políticas publicas estava centrada nas impressões pessoais dos candidatos a respeito delas, não em indicadores sociais ou econômicos, marcos legais ou dados orçamentários. Além disso, a viabilidade administrativa, jurídica e orçamentária das propostas sugeridas pelos candidatos não foi trazida para o noticiário como era de se esperar, pois os jornalistas tinham à sua disposição informações para formular esse questionamento. Questões como a participação popular na gestão das políticas, sua eficácia e transparência praticamente não foram mencionadas.

O recurso de contar casos e histórias pessoais de meninos ou meninas beneficiários (ou não) das políticas públicas, procedimento jornalístico que poderia enriquecer a cobertura, foi pouco utilizado. Não houve um esforço dos jornalistas neste sentido, talvez premidos pela rapidez do noticiário da campanha e pela ansiedade dos furos jornalísticos relacionados aos escândalos. Mais uma vez, infelizmente, o espetacular se impôs sobre a profundidade dos assuntos públicos na mídia.

A respeito da qualidade da informação, podemos concluir que o jornalismo brasileiro demonstrou amadurecimento e sensibilidade para incluir na cobertura eleitoral as urgentes questões sociais, antes ignoradas. Isso poderá ocasionar uma transferência paulatina da relevância dessa temática para a sociedade, e inverter futuras prioridades administrativas. Mas, o jornalismo brasileiro perdeu uma oportunidade única de utilizar a cobertura das eleições para aprofundar uma discussão publica sobre uma questão social urgente, comprometer os candidatos com suas promessas de campanha e assim poder cobrar posteriormente aos vencedores uma priorida- 
de para a agenda social. Os resultados da pesquisa confirmam a hipótese de Canela (2005): o avanço da mídia na cobertura social restringe-se à escolha de temas, enquanto todos os demais elementos para a construção de políticas publicas mais qualificadas continuam fortemente negligenciados.

Em relação ao agendamento e à relevância temática, discutidos no início deste artigo, nossa pesquisa não estabeleceu relações causais (nem foi desenhada para isso). Mas, levantou questões que merecem investigações posteriores. A insistência de um dos candidatos em uma única questão social relacionada à infância e adolescência (educação) parece ter agendado todo o debate eleitoral e contaminado a cobertura da mídia. Percebendo que não tinha chances de vitória, esse candidato presidencial declarou publicamente que o objetivo de sua candidatura era pautar a educação como tema da agenda pública nacional. Parece ter conseguido êxito no seu intento e agendado o debate eleitoral e sua cobertura.

Por outro lado, o trabalho persistente de agendamento da mídia parece também ter tido êxito em sensibilizar candidatos e pautar a cobertura. Essa rede de influências e agendamentos múltiplos foi sistematizada por Entman (2004) que utilizou a metáfora da cascata para descrevê-la: as influências fluem de degrau a degrau, sucessiva e mutuamente. ${ }^{7}$ Diz ele que a interface jornalistas-elitesdecision makers é um ponto chave na disseminação de informações e enquadramentos através da mídia. Mas, não é fácil determinar quem influencia quem. Os jornalistas conversam com suas fontes regulares, políticos e candidatos, checam outras, trocam idéias com os seus pares. Cada um dos nós do fluxo de informação tem poderes diferentes sobre diversas questões. No Brasil, nos últimos anos, a mobilização da sociedade civil trouxe temas sociais novos para a agenda pública e a mídia parece ser sensível a este agendamento difuso, mas persistente.

Isso demonstra que, pautados de maneira sistemática, os candidatos trouxeram assuntos relativos às crianças e adolescentes para a campanha e a mídia deu destaque a eles. O aumento é ainda

\footnotetext{
${ }^{7}$ ENTMAN, Robert. Projections of Power. Chicago: University of Chicago Press, 2004. O autor, entretanto, descreve a metáfora da cascada referindo-se especificamente aos enquadramentos jornalísticos.
} 
mais significativo se levarmos em conta que, durante o transcurso da campanha, a mídia foi tomada por um frenesi de denuncismo e escândalos artificialmente amplificados, que repercutiam politicamente e reverberavam novamente na cobertura, ofuscando discussões de propostas e programas sociais dos candidatos.

Em nosso estudo, os índices relativamente altos dos temas relacionados à infância e adolescência (incluindo educação e exclusão social) durante o período eleitoral podem ser, parcialmente pelo menos, creditados ao trabalho persistente de agendamento da mídia pelas $\mathrm{ONG}$ e organismos internacionais. Além da influência cumulativa, vale lembrar que durante o ano eleitoral de 2006 o trabalho de agendamento foi intensificado junto às redações tanto quanto junto aos comitês eleitorais dos candidatos. Houve um esforço de sensibilização e temas que nunca apareciam na cobertura jornalística como "marco legal, jurídico e institucional" apareceram com índices baixos, mas reveladores.

A quantidade da informação ofertada cresceu. A inserção de questões sociais na agenda da mídia parece, portanto, ser resultado de um círculo de influências mútuas, mais que de efeitos em cascata, que fluem do alto para baixo. A transferência programada desses temas das ONGs para a agenda da mídia ao longo dos últimos anos pode ter estimulado a sociedade a pressionar por novas políticas públicas. A implementação dessas políticas reverberou na campanha presidencial e, somado ao agendamento imediato, resultou numa cobertura jornalística relativamente mais qualificada, embora exista ainda muitos vícios arraigados na prática do jornalismo brasileiro que impedem uma virada de qualidade mais significativa.

\section{REFERÊNCIAS}

VIVARTA, Veet. Que país é este? São Paulo: Cortez Editora, 2003.

ENTMAN, Robert M. Projections of power - framing news, public opinion and U.S

foreign policy. Chicago: University of Chicago Press, 2004.

JORGE, V. Lombardo. A cobertura do Congresso Nacional pelos jornais brasileiros 1985-1990, Estudos Históricos No. 31, 2003. 
McCOMBS, Maxwell. Estableciendo la agenda - El impacto de los médios em la opinión publica y em el conocimiento. Barcelona: Paidós, 2006

MOTTA, Luiz G. Crise política - a mídia pode mais que os partidos? Observatório Mídia\&Política, 2005.

THOMPSON, John B. A mídia e a modernidade - uma teoria social da mídia. Petrópolis: Vozes, 1998.

WINTER, James; EYAL, Chaim. Agenda setting for the civil rights issues, Public Opinion Quarterly, 45, 1981.

Recebido em: 03/08/2010

Aceito em: 02/03/2011 